\title{
Uso, ocupação das terras e banco de dados geográficos da metade sul do Rio Grande do Sul
}

\author{
Land use and occupation and geographical data base of the half south of the \\ Rio Grande do Sul State
}

\author{
Édson Luis Bolfe ${ }^{\mathrm{I}}$ Otávio João Wachholz de Siqueira' ${ }^{\mathrm{II}}$ Rudiney Soares Pereira ${ }^{\mathrm{III}}$ \\ José Maria Filippini Alba ${ }^{\text {IV }}$ Adalberto Koiti Miura ${ }^{\mathrm{IV}}$
}

RESUMO

Banco de dados geográficos constitui-se em uma referência importante para o planejamento territorial, principalmente quando as informações regionais disponíveis são muito restritas. Os objetivos deste estudo foram quantificar e avaliar o uso e a ocupação das terras de 35 municípios do sul do Rio Grande do Sul. Instrumentais envolvendo geoprocessamento e sensoriamento remoto foram utilizados para classificar digitalmente imagens do satélite Landsat. Foi elaborado um banco de dados geográficos com informações referentes às classes de uso e à ocupação das terras (pastagem natural e cultivada, floresta natural, reflorestamento, banhado e alagadiço, dunas e areia; lâmina d’água; agricultura/solo exposto e área urbana). Os dados foram analisados por município e integrados na forma de instrumentos públicos de gestão territorial (Conselho Regional de Desenvolvimento da Região Sul, Associação dos Municípios da Zona Sul e Bacia Hidrográfica da Lagoa Mirim). Pastagens e agricultura foram as classes mais expressivas e corresponderam a 83\% dos valores médios dos municípios. As demais classes não ultrapassaram 5\% de ocupação. A análise espacial dos dados e as informações geradas possibilitam a compreensão da dinâmica ocupacional e permitem subsidiar a ordenação do espaço geográfico e o desenvolvimento sustentável da região.

Palavras-chave: geoprocessamento, ocupação das terras, planejamento territorial.

\section{ABSTRACT}

Geographical data base consist in an important reference for the territorial planning, mainly when the available regional information are restricted. This study objectified to quantify and evaluate the land use and occupation of 35 municipalities of the South of the Rio Grande do Sul state. Remote Sensing and Geoprocessing techniques were utilized to classify digital image of the Landsat satellite. Geographical data base were elaborated with concerning information the classes of use and land occupation (natural and cultivated pastures, natural forest, reforestation, swampy and drenched, dunes and sand, water, agriculture, uncover soil and urban areas). The data were analyzed by municipality and integrated in form of public instruments of territorial magement the for the Regional Committee of development of the South Region, for the Municipalities Association of the South Zone of the RS State and for the Lagoa Mirim Water Basin. Pastures and agriculture were the classes most expressive and corresponded $83 \%$ of the average securities of the municipalities, being the other classes less expressive $(<5 \%)$. Spatial analysis data and the information generated make possible the understanding of the occupational dynamics and subsidize the ordenation of the geographical space and the sustainable development of the region.

Key words: geoprocessing, land occupation, territorial planning.

\section{INTRODUÇÃO}

A crescente demanda interna e externa de produtos agropecuários tem gerado expansão da fronteira agrícola no país. A agricultura brasileira tem passado por um intenso processo de modernização nas últimas décadas, resultante de diversas políticas governamentais, como crédito subsidiado, preços mínimos de garantia, pesquisa e extensão rural (VICENTE et al., 2001). Porém, segundo OLIVETTE et

IEmpresa Brasileira de Pesquisa Agropecuária (EMBRAPA Tabuleiros Costeiros). Instituto de Geociências, Universidade Estadua de Campinas (UNICAMP), 13083-970, Campinas, SP, Brasil. E-mail: bolfe@cpatc.embrapa.br. Autor para correspondência.

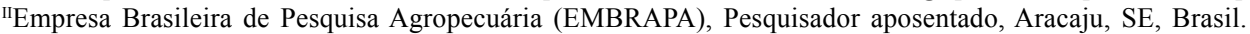

"IIDepartamento de Engenharia Rural, Centro de Ciências Rurais (CCR), Universidade Federal de Santa Maria (UFSM), Santa Maria, RS, Brasil.

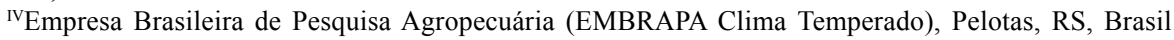


al. (2002), a distribuição da produção agropecuária brasileira é heterogênea, e inúmeros fatores estão relacionados com a vocação agrícola. Dentre esses fatores, destacam-se as condições edafoclimáticas e tecnológicas, a mão-de-obra disponível e o mercado, gerando diferentes padrões de uso e ocupação das terras.

No Rio Grande do Sul, quando se compara a região Sul e a Norte do Estado, evidenciam-se diferenças marcantes associadas ao processo de uso e ocupação das terras. A "metade norte" foi ocupada principalmente por imigrantes de origem européia ou por seus descendentes, baseando-se na pequena propriedade, onde predomina a agricultura familiar. Já a região denominada "metade sul", apresenta estrutura fundiária com maior concentração de médias e grandes propriedades ocupadas, principalmente, pelos cultivos de arroz irrigado e pela pecuária extensiva (SCHNEIDER \& FIALHO, 2000).

Instrumentos como os Comitês de Bacias Hidrográficas (BRASIL, 1997), o Programa Nacional de Desenvolvimento Sustentável de Territórios Rurais (BRASIL, 2003) e as entidades regionais como os Conselhos Regionais de Desenvolvimento e as Associações de Municípios refletem uma necessidade normativa para que determinada região passe a ser entendida como um território, ou seja, uma unidade de referência de observação, atuação, gestão e planejamento territorial por parte do poder público. Assim, a ocupação agropecuária, o uso da terra e as políticas agrícolas e agrárias têm sido objeto constante de estudos de instituições governamentais e não governamentais. Nesse contexto, é crescente o interesse de pesquisadores em explicar o desenvolvimento (social e econômico) diferenciado entre as regiões rurais do Rio Grande do Sul. Segundo SCHNEIDER \& TARTARUGA (2004), técnicas informatizadas de análise espacial passaram a obter elevado destaque e serem apontadas por muitos estudiosos como de fundamental relevância para se compreender o dinamismo do uso e da ocupação das terras.

Dentre as técnicas, destaca-se a utilização de banco de dados geográficos em ambiente computacional dos sistemas de informações geográficas (SIG), os quais, segundo BURROUGH (1989), são aplicativos constituídos de cinco módulos, em que cada módulo é um subsistema que permite as operações de entrada e verificação de dados; armazenamento e gerenciamento de banco de dados, apresentação e saída de dados, transformação de dados e interação com o usuário. Esses sistemas se diferenciam de outros tipos de sistemas de informação pelas funções que realizam no contexto da análise espacial. Tais funções utilizam os atributos espaciais e não espaciais das entidades gráficas armazenadas no banco de dados e fazem simulações (modelos) sobre os fenômenos do mundo real, seus aspectos ou parâmetros (CÂMARA \& MEDEIROS, 2003).

Dessa forma, ao realizar o mapeamento e o monitoramento das áreas agropecuárias, objetivando gerar dados para fins de planejamento territorial rural e controle ambiental, torna-se imprescindível obter avaliações qualitativas e quantitativas em escalas municipais e regionais, especialmente quando se almeja analisar a distribuição espacial de componentes de uso e ocupação das terras.

Tradicionalmente o levantamento e a qualificação dos fatores de uso e ocupação das terras são dificultados por demandarem fluxos expressivos de informações, que requerem alocação, detalhamentos, organização, interpretação e, principalmente, armazenamento adequado que assegure a confiabilidade do banco de dados geográficos. Segundo ASSAD \& SANO (1998), esse banco de dados é um conjunto de arquivos estruturados que facilita o acesso a conjuntos de informações que descrevem determinadas entidades do mundo. Torna-se possível sistematizar tais informações por meio da utilização do sensoriamento remoto e de técnicas de geoprocessamento.

NOVO (1992) compreende o sensoriamento remoto como sendo a utilização conjunta de sensores e o processamento dos dados orbitais, com o objetivo de estudar o ambiente terrestre por meio do registro e da análise das interações entre a radiação eletromagnética e as substâncias componentes do planeta Terra em suas mais diversas manifestações. Assim, a aplicação de técnicas de geoprocessamento é extremamente útil para o planejamento municipal, pois reúne aplicativos que permitem coletar, armazenar, recuperar, transformar, inferir e representar visualmente dados espaciais e também estatísticos e textuais a eles relacionados, a partir de uma base de dados georeferenciada (XAVIER, 2000).

O levantamento e a análise do uso e da ocupação das terras no Brasil, em especial na região Sul do Rio Grande do Sul, é fundamental para a compreensão dos padrões de organização do espaço e motiva a busca de metodologias e escalas mais apropriadas na elaboração de mapeamentos temáticos. Os dados gerados por esses mapeamentos são relevantes para o conhecimento da dinâmica ocupacional, amparando programas de desenvolvimento regional em suas diferentes escalas. $\mathrm{O}$ monitoramento direcionado à atualização de 
informações sobre o uso e a ocupação das terras assume importância na medida em que detecta usos desordenados, causadores de deterioração no ambiente. As informações decorrentes oferecem suporte ao planejamento e à execução de ações técnicas, na medida em que incorporam dados históricos do uso da terra. Nesse sentido, inserem-se os SIG e os bancos de dados geográficos como eficientes ferramentas de suporte ao planejamento territorial rural.

Assim, este artigo objetiva estabelecer possíveis contribuições para o aporte quantitativo e analítico sobre o levantamento do uso e da ocupação das terras da região Sul do Estado do Rio Grande do Sul, enfatizando a utilização de geotecnologias como fonte geradora de dados e informações na escala municipal e de gestão integrada do espaço geográfico.

\section{MATERIAL E MÉTODOS}

A área de estudo abrange a região Sul do Rio Grande do Sul, situada entre as coordenadas $55^{\circ}$ $00^{\prime} / 50^{\circ} 10^{\prime} \mathrm{W}$ e $30^{\circ} 30^{\prime} / 33^{\circ} 45^{\prime} \mathrm{S}$ e integrando 35 municípios: Aceguá, Amaral Ferrador, Arambaré, Arroio do Padre, Arroio Grande, Bagé, Camaquã, Candiota, Canguçu, Capão do Leão, Cerrito, Cerro Grande do Sul, Chuí, Chuvisca, Cristal, Encruzilhada do Sul, Herval, Hulha Negra, Jaguarão, Morro Redondo, Mostardas, Pedras Altas, Pedro Osório, Pelotas, Pinheiro Machado, Piratini, Rio Grande, Santa Vitória do Palmar, Santana da Boa Vista, São José do Norte, São Lourenço do Sul, Sentinela do Sul, Tapes, Tavares e Turuçu. Foram utilizadas imagens do sensor remoto Thematic Mapper -TM/Landsat 5 (bandas espectrais 3, 4 e 5, das cenas: $221.081,221.082,221.083,222.081,222.082,222.083 \mathrm{e}$ 223.082), folhas sistemáticas da DSG/1:50.000, sistema de informações geográficas, banco de dados e sistema de posicionamento global por satélite - GPS. Para a consecução das ações, as atividades foram divididas nas seguintes etapas: a) tratamento digital e registro de imagens, b) classificação temática de uso e ocupação das terras, c) digitalização da base cartográfica e d) geração de banco de dados e análises espaciais.

Para o tratamento digital e registro das imagens, efetuou-se pesquisa junto ao INPE (Instituto Nacional de Pesquisas Espaciais), buscando informações das imagens TM a partir de 1995, com condições visuais favoráveis (baixa cobertura de nuvens), sendo obtidas imagens no período compreendido entre 1996 e 2003 . Posteriormente, foram processadas digitalmente as diferentes bandas espectrais, banda $3(0,63-0,69 \mu \mathrm{m})$, banda $4(0,76-0,90 \mu \mathrm{m})$ e banda $5(1,55-1,75 \mu \mathrm{m})$ de intervalo espectral. Em seguida, foi elaborada uma coleção de composições coloridas, sendo associadas as três bandas espectrais a cada uma das três cores primárias: azul, verde e vermelho, buscando, assim a melhor identificação das diferentes classes de uso da terra. Após esse procedimento, as composições foram corrigidas geometricamente pelo polinômio cúbico e pelas coordenadas geográficas obtidas nas folhas sistemáticas.

$\mathrm{Na}$ etapa de classificação temática de uso e ocupação das terras, utilizou-se a classificação digital supervisionada pelo método de máxima verossimilhança (CRÓSTA, 2002), obtida em função do conhecimento prévio de padrões espectrais das áreas amostrais coletadas in loco. Isso permitiu a seleção de áreas de treinamento confiáveis, definindo-se que o algoritmo classificador operasse com base na distribuição de probabilidade de cada classe, realizada em função das classes de interesse (pastagem natural e cultivada, floresta natural, reflorestamento, banhado e alagadiço, dunas e areia; lâmina d'água; agricultura/solo exposto e área urbana). Por meio desse método, a distribuição espectral das diferentes classes é considerada como normal, ou seja, gaussianas. A quantificação das áreas dos diferentes usos e de ocupação das terras foi baseada a partir da contagem do número de pixels classificados em cada uma das classes de interesse. Considerando a resolução espacial de $30 \mathrm{~m}$ mapearam-se áreas iguais ou superiores a 0,09ha. Essas etapas foram realizadas utilizando-se os SIG ArcGis 9.0 e Idrisi for Windows 32. Posteriormente, foi realizada a aferição do mapeamento temático em campo, utilizando-se os padrões de resposta espectral das imagens e da classificação digital. Esse procedimento partiu de uma amostragem sistemática, em que foram obtidos 109 pontos de controle, sendo calculada posteriormente a Exatidão Global $(\mathrm{G})$ a partir da razão entre o somatório dos pontos corretamente classificados e o número total de pontos controle (BRITES et al., 1996).

No processo de digitalização e construção da base cartográfica, realizado a partir do aplicativo CartaLinx, foram utilizadas as folhas sistemáticas, sendo obtidas informações referentes à rede viária, à rede hidrográfica, à altimetria, à divisão municipal e às manchas urbanas, sendo estas últimas atualizadas a partir das composições coloridas. Posteriormente, formatou-se o BDG com as informações geocodificadas de uso e ocupação das terras dos municípios, utilizandose o sistema DataBase Workshop do SIG Idrisi for Windows 32, sendo inseridos os dados obtidos durante a etapa de classificação temática e de quantificação de uso e ocupação das terras. 
Foram integrados ainda ao BDG os dados dos municípios na forma de três instrumentos públicos de gestão territorial: 1) Conselho Regional de Desenvolvimento da Região Sul (RIO GRANDE DO SUL, 1994a), fórum de discussão e de decisão, que objetiva a promoção do desenvolvimento regional, harmônico e sustentável, por meio da integração dos recursos e das ações de governo na região; 2) Associação dos Municípios da Zona Sul (AZONASUL, 2006), que objetiva realizar ações integradas, visando ao desenvolvimento econômico, social e cultural da região, e promover levantamentos e estudos voltados ao desenvolvimento regional; e 3) Comitê da Bacia Hidrográfica da Lagoa Mirim (RIO GRANDE DO SUL, 1994b), o qual objetiva a gestão participativa e descentralizada dos recursos hídricos por meio da implementação dos instrumentos técnicos de gestão, da negociação de conflitos e da promoção dos usos múltiplos da água, integrando ações governamentais. Por fim, visando analisar espacialmente a distribuição das diferentes classes de uso e ocupação, foram utilizados diferentes procedimentos em ambiente de SIG: consultas espaciais a partir das informações geocodificadas e dos dados vetoriais via linguagem SQL (Linguagem de Consulta Estruturada), operadores de contexto, operadores matemáticos e avaliações estatísticas. Alguns resultados foram analisados considerando informações do Atlas Socioeconômico do RS de 2005 e do Censo Agropecuário de 2006, por serem estudos com datas próximas às da maioria das datas das imagens de satélites utilizadas.

\section{RESULTADOS E DISCUSSÃO}

No processo de correção geométrica utilizando polinômio cúbico, o erro médio quadrático obtido em todas as cenas foi abaixo de $15 \mathrm{~m}$, ou seja, inferior à metade da resolução espacial do pixel (30m), padrão sugerido por EASTMAN (1994). Na aferição do mapeamento, verificou-se que, dos 109 pontos de controle avaliados, 96 pontos foram corretamente classificados, obtendo-se assim a Exatidão Global de $88,07 \%$, valor acima do patamar mínimo (85\%) estabelecido por JENSEN (1996).

Foram verificadas, para os 35 municípios estudados (Tabela 1), as áreas abrangidas pelas diferentes classes de uso e ocupação das terras e a forma de gestão territorial. Na tabela 2, são disponibilizados os descritores estatísticos associados. A área média dos municípios corresponde a $1497 \mathrm{~km}^{2}$, variando entre $124 \mathrm{~km}^{2}$ (Arroio do Padre) e $5241 \mathrm{~km}^{2}$ (Santa Vitória do Palmar). Esses municípios integram três das cinco macrozonas definidas pelo macrozoneamento ambiental do Estado (UFRGS, 2001): a) Escudo Sul-rio-grandense, onde predominam áreas de campos subarbustivos e de campos mistos com ocorrência de matas-galerias e de encostas; b) Planície Costeira, ocorrendo áreas de depósitos arenosos e cordões de dunas, lagoas e lagunas, zona agrícola de uso intensivo de verão e zona agrícola de culturas diversificadas; e c) Depressão Central, a qual é constituída predominantemente de áreas de campos limpos e pastagens, zona agrícola de uso intensivo de verão e zona agrícola de culturas diversificadas.

Pastagens naturais/cultivadas e agricultura/ solo exposto constituíram-se nas classes de ocupação mais expressivas, correspondendo, no total dos 35 municípios, respectivamente, a 26.012 e $16.901 \mathrm{~km}^{2}$, representando em média $83 \%$ das áreas municipais. Essas classes de usos estão condicionadas aos padrões culturais e as condições edafoclimáticas encontradas nesses municípios, que proporcionaram à região sul a obtenção da segunda maior concentração de rebanho bovino e a segunda maior produção de arroz do Estado entre 2004 e 2005, com 12,7\% e 16,3\% respectivamente, atrás da região Fronteira Oeste, com $24,2 \%$ do rebanho bovino e $36,5 \%$ da produção de arroz (RIO GRANDE DO SUL, 2005).

Encontra-se representada (Figura 1) a expressividade relativa, em âmbito municipal, das diversas classes de ocupação das terras. As maiores áreas com ocupação de pastagens foram detectadas nos Municípios de Bagé $\left(2825 \mathrm{~km}^{2}\right)$ e de Santa Vitória do Palmar $\left(2275 \mathrm{~km}^{2}\right)$ (Tabela 1). Esses valores são superiores aos apontados pelo IBGE (2006), 2080 e $1913 \mathrm{~km}^{2}$, respectivamente, provavelmente em função de o censo agropecuário considerar apenas as áreas de pastagens naturais, ao contrário da metodologia aqui explanada, que quantificou também as pastagens cultivadas. No entanto, ao considerar a distribuição relativa, destacam-se os municípios de Pedro Osório, Aceguá, Pedras Altas, Bagé e Jaguarão, situados nas regiões fronteiriças do Uruguai, alcançando percentuais entre 50 e $80 \%$ do total da área municipal. As áreas classificadas nas imagens como pastagens naturais estão associadas aos campos limpos (tapetes herbáceos baixos e densos com presença de matas galerias remanescentes); campos mistos (tapetes herbáceos e subarbustivos com ocorrência de matas galerias remanescentes) campos subarbustivos (cobertura de gramíneas e ciperáceas com ou sem áreas agrícolas intercaladas) (UFRGS, 2001).

As áreas mais extensas correspondentes à agricultura e ao solo exposto foram detectadas nos Municípios de Encruzilhada do Sul $\left(1598 \mathrm{~km}^{2}\right)$, Canguçu $\left(1458 \mathrm{~km}^{2}\right)$ e Piratini $\left(1435 \mathrm{~km}^{2}\right)$, com valores acima dos 
Tabela 1 - Áreas de uso e ocupação das terras por município $\left(\mathrm{km}^{2}\right)$ e gestão territorial (AZONASUL - A; BH da Lagoa Mirim - B e COREDESUL - C).

\begin{tabular}{|c|c|c|c|c|c|c|c|c|c|c|c|}
\hline Município & Gestão & PNC & FN & RF & $\mathrm{BA}$ & DA & LD & ASE & $\mathrm{CN}$ & $\mathrm{AU}$ & Total \\
\hline Aceguá & $\mathrm{AB}$ & 1110 & 21 & 28 & 36 & 52 & 18 & 286 & $<1$ & 1 & 1551 \\
\hline Amaral Ferrador & $\mathrm{AC}$ & 229 & 50 & 9 & 2 & $<1$ & $<1$ & 218 & $<1$ & 1 & 509 \\
\hline Arambaré & $\mathrm{B}$ & 228 & 12 & 28 & 21 & 2 & 20 & 206 & $<1$ & 2 & 519 \\
\hline Arroio do Padre & $\mathrm{ABC}$ & 47 & 19 & 13 & $<1$ & $<1$ & $<1$ & 45 & $<1$ & $<1$ & 124 \\
\hline Arroio Grande & $\mathrm{ABC}$ & 1395 & 27 & 110 & 87 & 43 & 48 & 798 & 5 & 6 & 2519 \\
\hline Bagé & B & 2825 & 51 & 153 & 110 & 67 & 23 & 865 & $<1$ & 33 & 4127 \\
\hline Camaquã & $\mathrm{B}$ & 714 & 134 & 104 & 48 & 4 & 26 & 623 & $<1$ & 14 & 1668 \\
\hline Candiota & $\mathrm{B}$ & 577 & 13 & 27 & 11 & 19 & 3 & 285 & 1 & 3 & 939 \\
\hline Canguçu & $\mathrm{ABC}$ & 1647 & 205 & 191 & 12 & 1 & 2 & 1458 & $<1$ & 3 & 3518 \\
\hline Capão do Leão & $\mathrm{ABC}$ & 408 & 30 & 45 & 32 & 3 & 16 & 246 & $<1$ & 4 & 783 \\
\hline Cerrito & $\mathrm{ABC}$ & 309 & 22 & 14 & 2 & $<1$ & 1 & 116 & $<1$ & 1 & 465 \\
\hline Cerro Grande do Sul & $\mathrm{B}$ & 129 & 22 & 14 & 3 & 3 & 1 & 111 & $<1$ & 1 & 285 \\
\hline Chuí & $\mathrm{ABC}$ & 136 & $<1$ & $<1$ & 17 & 4 & $<1$ & 41 & 7 & 2 & 207 \\
\hline Chuvisca & $\mathrm{B}$ & 77 & 25 & 9 & $<1$ & $<1$ & $<1$ & 91 & $<1$ & $<1$ & 202 \\
\hline Cristal & $\mathrm{B}$ & 318 & 96 & 28 & 8 & 3 & 7 & 218 & $<1$ & 2 & 681 \\
\hline Encruzilhada do Sul & $\mathrm{A}$ & 1132 & 121 & 514 & 38 & 2 & 1 & 1598 & $<1$ & 6 & 3413 \\
\hline Herval & $\mathrm{ABC}$ & 1104 & 53 & 108 & 3 & 2 & 2 & 480 & $<1$ & 2 & 1754 \\
\hline Hulha Negra & $\mathrm{B}$ & 488 & 5 & 16 & 13 & 17 & 2 & 279 & $<1$ & 1 & 821 \\
\hline Jaguarão & $\mathrm{ABC}$ & 1399 & 11 & 28 & 84 & 36 & 18 & 463 & 2 & 10 & 2052 \\
\hline Morro Redondo & $\mathrm{ABC}$ & 129 & 17 & 16 & $<1$ & $<1$ & $<1$ & 84 & $<1$ & $<1$ & 246 \\
\hline Mostardas & $\mathrm{B}$ & 283 & 17 & 89 & 125 & 212 & 30 & 1055 & 166 & 4 & 1982 \\
\hline Pedras Altas & $\mathrm{ABC}$ & 952 & 22 & 32 & 13 & 16 & 3 & 339 & $<1$ & 1 & 1376 \\
\hline Pedro Osório & $\mathrm{ABC}$ & 469 & 14 & 12 & 5 & $<1$ & 8 & 91 & $<1$ & 3 & 603 \\
\hline Pelotas & $\mathrm{ABC}$ & 702 & 83 & 115 & 26 & 7 & 19 & 540 & 1 & 63 & 1555 \\
\hline Pinheiro Machado & $\mathrm{ABC}$ & 1285 & 21 & 140 & 18 & 8 & $<1$ & 775 & $<1$ & 3 & 2250 \\
\hline Piratini & $\mathrm{ABC}$ & 1527 & 139 & 415 & 21 & 5 & $<1$ & 1435 & $<1$ & 3 & 3545 \\
\hline Rio Grande & $\mathrm{ABC}$ & 1164 & 7 & 163 & 223 & 40 & 196 & 970 & 28 & 47 & 2838 \\
\hline Santa Vit. do Palmar & $\mathrm{ABC}$ & 2275 & 5 & 91 & 607 & 151 & 873 & 904 & 326 & 9 & 5241 \\
\hline Santana da Boa Vista & $\mathrm{AC}$ & 701 & 4 & 195 & 22 & 2 & 1 & 516 & $<1$ & 1 & 1443 \\
\hline São José do Norte & $\mathrm{ABC}$ & 465 & 2 & 89 & 50 & 94 & 49 & 294 & 101 & 2 & 1147 \\
\hline São Lourenço do Sul & $\mathrm{AC}$ & 1074 & 141 & 91 & 28 & 5 & 20 & 672 & $<1$ & 7 & 2038 \\
\hline Sentinela do Sul & $\mathrm{B}$ & 62 & 49 & 30 & 1 & 1 & $<1$ & 175 & $<1$ & 1 & 318 \\
\hline Tapes & $\mathrm{B}$ & 284 & 26 & 73 & 25 & 11 & 28 & 338 & 14 & 5 & 805 \\
\hline Tavares & $\mathrm{C}$ & 214 & 9 & 36 & 11 & 28 & 26 & 220 & 60 & 1 & 606 \\
\hline Turuçu & $\mathrm{ABC}$ & 150 & 10 & 14 & 8 & 3 & 1 & 67 & 1 & $<1$ & 253 \\
\hline
\end{tabular}

PNC: pastagem natural e cultivada; FN: floresta natural; RF: reflorestamento; BA: banhado e alagadiço; DA: dunas e areia; LD: lâmina d'água; ASE: agricultura e solo exposto; $\mathrm{CN}$ : cobertura de nuvens; AU: área urbana.

levantados pelo IBGE (2006), 270, 797 e $260 \mathrm{~km}^{2}$, sendo provavelmente associadas à grande presença de solos com afloramentos rochosos nesses municípios, classificadas na mesma classe de ocupação em função da resposta espectral das imagens utilizadas (Tabela 1). Em termos relativos, destacaram-se os Municípios de Sentinela do Sul, Mostardas e Encruzilhada do Sul. Porém, os percentuais máximos são inferiores a $60 \%$. Nas áreas classificadas como agricultura, condicionadas aos fatores edafoclimáticos regionais, destacam-se os cultivos intensivos de verão, com predominância do arroz irrigado e, em segundo plano, as áreas com cultivos intensivos de verão e inverno, com milho, feijão, hortifrutigranjeiros e fruticultura.

As maiores áreas com florestas naturais foram detectadas nos Municípios de Canguçu, São Lourenço do Sul, Piratini, Camaquã e Encruzilhada do Sul, restringindo-se, no entanto, a um percentual máximo em âmbito municipal inferior a $16 \%$, sobressaindo-se, nesse contexto, os Municípios de Sentinela do Sul, Arroio do Padre, Cristal, Chuvisca e Amaral Ferrador. As áreas mais expressivas com reflorestamentos (pinus, acácia, eucalipto) foram detectadas em Encruzilhada do Sul e Piratini (Tabela 1), representando, no máximo, $15 \%$ da área municipal, destacando-se em termos relativos os Municípios de Encruzilhada do Sul, Santana da Boa Vista e Piratini. Considerando essas duas classes de ocupação (florestas naturais e reflorestamentos), os Municípios de Encruzilhada do Sul $\left(635 \mathrm{~km}^{2}\right)$ e Piratini $\left(554 \mathrm{~km}^{2}\right)$ apresentaram a maior cobertura florestal, enquanto que, segundo o IBGE (2006), essas duas classes abrangem 591 e $373 \mathrm{~km}^{2}$, respectivamente. Como as maiores áreas estão relacionadas aos reflorestamentos empresariais da região, que visam à produção de carvão vegetal e ao abastecimento para indústrias de celulose e papel, 
Tabela 2 - Total e descritores estatísticos por tipo de uso e ocupação das terras.

\begin{tabular}{lllllllllll}
\hline Descritor Estatístico & PNC & FN & RF & BA & DA & LD & ASE & CN & AU & Total \\
\hline Total $\left(\mathrm{km}^{2}\right):$ & 26012 & 1479 & 3038 & 1710 & 843 & 1444 & 16901 & 715 & 240 & 52381 \\
Máximo $\left(\mathrm{km}^{2}\right):$ & 2825 & 205 & 514 & 607 & 212 & 873 & 1598 & 326 & 63 & 5241 \\
Mínimo $\left(\mathrm{km}^{2}\right):$ & 47 & $<1$ & $<1$ & $<1$ & $<1$ & $<1$ & 41 & $<1$ & $<1$ & 124 \\
Média $\left(\mathrm{km}^{2}\right):$ & 743 & 42 & 87 & 49 & 24 & 41 & 483 & 20 & 7 & 1497 \\
Máximo $(\%):$ & 78 & 15 & 15 & 12 & 11 & 17 & 55 & 10 & 4 & - \\
Mínimo $(\%):$ & 14 & $<1$ & $<1$ & $<1$ & $<1$ & $<1$ & 15 & $<1$ & $<1$ & - \\
Média $(\%):$ & 50 & 4 & 5 & 2 & 1 & 2 & 33 & 1 & $<1$ & - \\
\hline
\end{tabular}

PNC: pastagem natural e cultivada; FN: floresta natural; RF: reflorestamento; BA: banhado e alagadiço; DA: dunas e areia; LD: lâmina d'água; ASE: agricultura e solo exposto; CN: cobertura de nuvens; AU: área urbana.

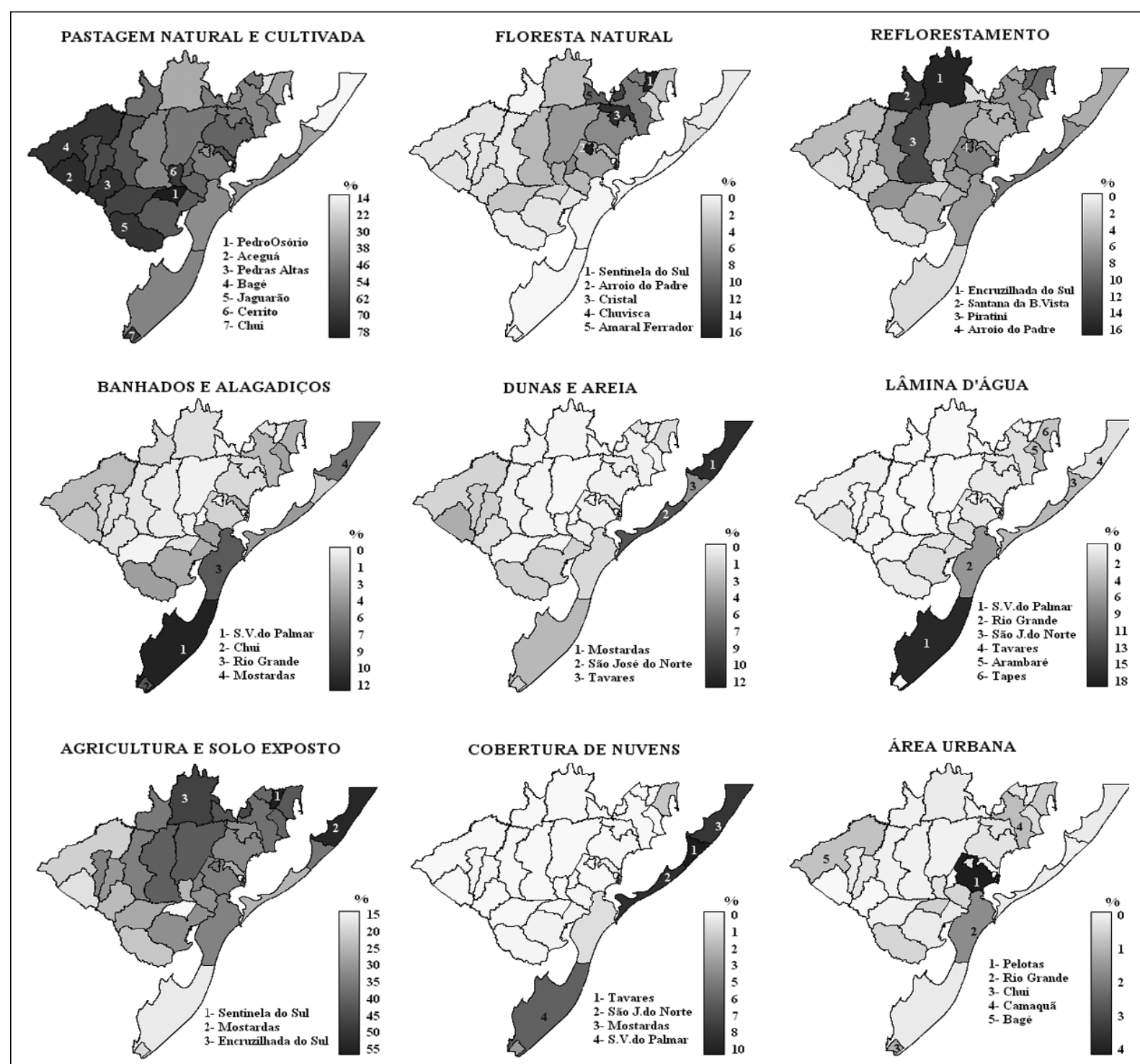

Figura 1 - Distribuição das classes de uso e ocupação das terras para os 35 municípios do extremo Sul do Rio Grande do Sul, imagens Landsat TM-5 obtidas entre 1996 e 2003.

Ciência Rural, v.39, n.6, set, 2009. 
as quais possuem controle das áreas implantadas; o valor inferior apontado pelo IBGE está provavelmente relacionado à dificuldade de obtenção das informações dos remanescentes florestais naturais.

Banhados e alagadiços foram especialmente detectados no Município de Santa Vitória do Palmar, coincidentemente com a maior concentração nesse município de áreas de cultivo de arroz irrigado. Esse município produziu $11,8 \%$ do arroz gaúcho entre 2001 e 2003, sendo o segundo maior produtor do Estado (RIO GRANDE DO SUL, 2005). Os percentuais dessa classe de ocupação são inferiores a 12\%, destacandose ainda os Municípios de Chuí, Rio Grande e Mostardas.

Dunas e areia foram evidenciadas principalmente em Mostardas, Santa Vitória do Palmar e São José do Norte, com percentual de ocupação municipal inferior a $11 \%$. As maiores extensões de área com lâminas d'água foram detectadas principalmente nos Municípios de Santa Vitória do Palmar e Rio Grande, com percentual de ocupação em âmbito municipal inferior a $17 \%$. Esses valores estão associados ao elevado número de barragens utilizadas para a cultura do arroz irrigado nesses municípios.

As áreas urbanas mais expressivas foram detectadas nos Municípios de Pelotas, Rio Grande e Bagé, com percentual máximo de ocupação em âmbito municipal de $4 \%$. A presença de nuvens foi mais evidenciada nos municípios litorâneos, correspondendo a valores percentuais máximos de $10 \%$ em Tavares (Tabela 1), significando, para essas regiões, incertezas de classificação de ocupação que devem ser avaliadas em trabalhos futuros.

É apresentada a distribuição geral das classes de uso e ocupação das terras referentes às regiões de abrangência do COREDESUL, da AZONASUL e da Bacia Hidrográfica da Lagoa Mirim (Figura 2). A distribuição relativa das diversas classes de ocupação foi muito semelhante nas três situações analisadas, destacando-se, conforme mencionado anteriormente, as classes referentes a pastagens, com $50 \%, 50 \%$ e $54 \%$, e as áreas com agricultura, com $31 \%$, $32 \%$ e $28 \%$, para o COREDESUL, a AZONASUL e a BH Lagoa Mirim, respectivamente. A análise do uso e da ocupação das terras está implicitamente ligada à Unidade Geopolítica, proporcionando uma avaliação integrada quanto à dinâmica ocupacional e sua interação com a economia, não apenas no âmbito municipal, mas também regional. Isso se reflete na reorganização da própria região, como na reestruturação do território estudado, induzindo o surgimento de novos espaços agropecuários, dadas as suas especificidades e potencialidades.
Assim sendo, entende-se que o estudo da superfície terrestre é de fundamental importância para as diversas ciências preocupadas em analisar as transformações do meio em decorrência da ação humana. O trabalho realizado por meio da aplicação de geotecnologias demonstrou ser um instrumental dotado de agilidade para o levantamento do uso e da ocupação das terras, podendo subsidiar decisões e envolvendo o planejamento e o desenvolvimento socioeconômico e ambiental adequado à metade sul do Rio Grande do Sul.

\section{CONCLUSÕES}

A utilização de imagens do sensor TM (Thematic Mapper) e sua classificação digital proporcionaram a elaboração de um banco de dados geográficos com informações sobre o uso e a ocupação das terras da região Sul do Estado do Rio Grande do Sul, demonstrando ser uma metodologia eficiente e capaz de suprir a necessidade de base de dados regional para fins de planejamento territorial rural.

Pastagens naturais e cultivadas constituíram a classe de ocupação mais expressiva, correspondendo a aproximadamente $50 \%$, na média dos 35 municípios, concentrando-se nas áreas expressivas na região fronteiriça com o Uruguai. Agricultura/solo exposto constituiu-se na segunda classe de ocupação das terras da região, com cobertura em âmbito municipal variando entre $15 \%$ e $55 \%$ e valores médios de cerca de $33 \%$, requerendo estudos complementares, tendo em vista a redução de incertezas associadas ao componente "solo exposto". Florestas naturais e reflorestamentos corresponderam respectivamente a $16 \%$ e $15 \%$ da ocupação municipal, em média. As classes de ocupação associadas a banhados/ alagadiços, a dunas/areia e à lâmina d'água atingiram no máximo $17 \%$ da cobertura municipal, tendo correspondido em média a uma área de cobertura municipal entre $1 \%$ e $2 \%$. Áreas urbanas atingiram no máximo 4\%, situando-se na média dos 35 municípios em valores inferiores a $1 \%$.

As informações qualitativas e quantitativas obtidas neste estudo, aliadas com informações de outras instituições de ensino e pesquisa, possibilitarão verificar a distribuição espacial dos componentes de uso e ocupação das terras, representando adicional suporte a zoneamentos territoriais da região.

\section{AGRADECIMENTOS}

Os autores agradecem à Embrapa Clima Temperado e ao Departamento de Engenharia Agrícola do Centro de Ciências Rurais da UFSM, respectivamente, por terem coordenado e 


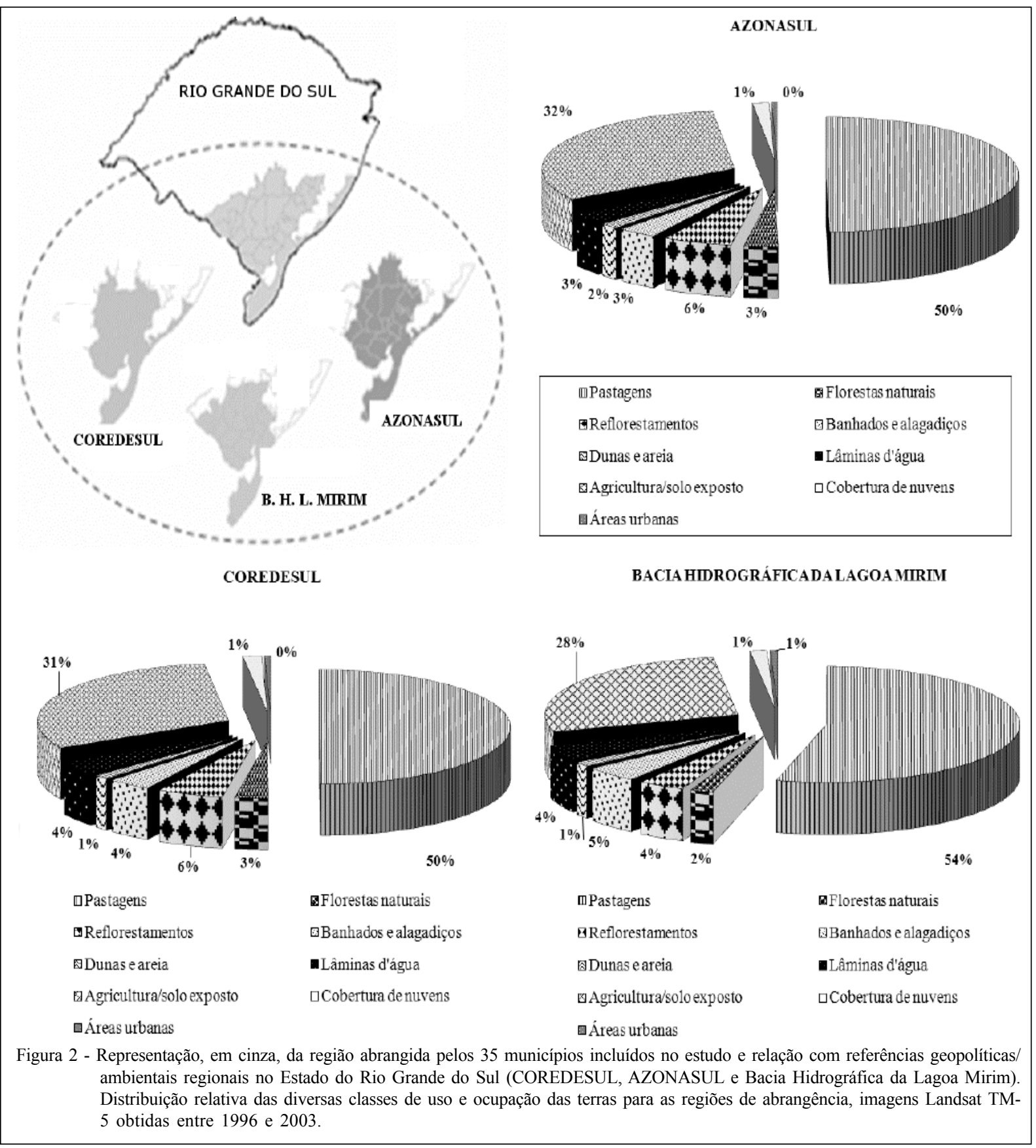

abrigado as ações do projeto, e à Fundação de Amparo à Pesquisa do Estado do Rio Grande do Sul (FAPERGS), pelo suporte financeiro viabilizado por meio do projeto: "Tecnologias e Informação para o Desenvolvimento do Extremo Sul, RS", dentre outros que foram fundamentais para o desenvolvimento da presente pesquisa.

\section{REFERÊNCIAS}

ASSAD, E.D.; SANO, E.E. Sistema de informações geográficas: aplicações na agricultura. 2.ed. Brasília: EMBRAPA, 1998. 434p.
AZONASUL (Associacão dos Municípios da Zona Sul do Estado do Rio Grande do Sul). Informações. Capturado em 10 jun. 2006. Online. Disponível na Internet: http://www.azonasul.org.br/ Informacoes $/ 3$.

BRASIL. Lei Federal n.9.433. Institui a Política Nacional de Recursos Hídricos, cria o Sistema Nacional de Gerenciamento de Recursos Hídricos. 8/1/1997. 1997.

BRASIL. Decreto Federal n.4.854. Dispõe sobre a composição, estruturação, competências e funcionamento do Conselho Nacional de Desenvolvimento Rural Sustentável. 8/ 10/2003. 2003.

Ciência Rural, v.39, n.6, set, 2009. 
BRITES, R.S. et al. Verificação da exatidão em classificação de uma imagem orbital mediante a utilização de três índices. Revista Árvore, v.20, n.3, p.415-424, 1996.

BURROUGH, P.A. Principles of geographical information systems for land resources assessment. Oxford: Clarendon, 1989. 194p.

CÂMARA, G.; MEDEIROS, J.S. DE. Operações de análise geográfica. In: ASSAD, E.D.; SANO, E.E. Sistema de informações geográficas. Brasília: EMBRAPA, 2003. Cap.5, p.67-91.

CRÓSTA, A.P. Processamento digital de imagens de sensoriamento remoto. 2.ed. Campinas: UNICAMP/IG, 2002. 154 p.

EASTMAN, J.R. Idrisi for Windows: exercícios tutorais Porto Alegre: UFRGS, 1994. 109p.

IBGE (Instituto Brasileiro de Geografia). Censo Agropecuário. 2006. Capturado em 15 jan. 2007. Online. Disponível na Internet: http://www.ibge.gov.br

JENSEN, J.R. Introductory digital image processing Englewood Cliffs: Prentice - Hall, 1996. 51p.

NOVO, E.M.L.M. Sensoriamento remoto. 2.ed. São Paulo: Edgard Blücher, 1992. 308p.
OLIVETTE, M.P. et al. Distribuição da área agrícola. Agricultura em São Paulo. v.49, n.1, p.95-125, 2002

RIO GRANDE DO SUL. Decreto Estadual n.35.764. Dispõe sobre os Conselhos Regionais de Desenvolvimento. 17/10/1994. 1994a.

RIO GRANDE DO SUL. Lei Estadual n.10.350. Institui o Sistema Estadual de Recursos Hídricos. 20/12/1994. 1994 b.

RIO GRANDE DO SUL. Atlas Socioeconômico do Rio Grande do Sul. 2005. Capturado em 13 out. 2008. Online. Disponível na Internet: http://www.scp.rs.gov.br/atlas.

SCHNEIDER, S.; TARTARUGA, I.G.P. Território e Abordagem Territorial: das referências cognitivas aos aportes aplicados à análise dos processos sociais rurais. Raízes. v.23, n.1, p.99116,2004

SCHNEIDER, S.; FIALHO, M.A.V. Pobreza rural, desequilíbrios regionais e desenvolvimento agrário no Rio Grande do Sul. Teoria e Evidência Econômica. v.8, n.15, p.117-149, 2000.

UFRGS (Universidade Federal do Rio Grande do Sul). Macrozoneamento ambiental do RS. 2001. Capturado em 13 out. 2008. Online. Disponível na Internet: http://www.scp.rs.gov.br/ uploads/Macrozoneamento.pdf.

VICENTE, J.R. et al. Produtividade agrícola No Brasil, 1970 1995. Agricultura em São Paulo. v.48, n.2, p.33-55, 2001.

XAVIER, S. Geoprocessamento e SIG's. Rio de Janeiro: IGEO, 2000. 104p. 